\title{
BENEFÍCIOS DO TRABALHO FORMAL PARA OS PRESTADORES DE SERVIÇOS EM OBRAS DE ALVENARIA NA CIDADE DE TANGARÁ DA SERRA/MT.
}

\author{
Ricardo de Almeida ${ }^{1}$ \\ Marcelo Evandro Alves ${ }^{2}$
}

\section{RESUMO}

O estudo teve como objetivo verificar a importância da formalização dos trabalhadores que prestam serviços em obras de alvenaria em Tangará da Serra - MT. Se tratando de termos metodológicos, a pesquisa se caracterizou como descritiva, quantitativa e exploratória, deu-se através da pesquisa de campo, no qual foi aplicado questionário a 40 microempreendedores da área de obras de alvenaria devidamente formalizados na cidade de Tangará da Serra - MT. O referencial teórico abordou os conceitos de empreendedorismo, microempreendedor individual; conceito e objetivos do governo ao incluir a figura do Microempreendedor Individual, o processo de formalização do MEI e as definições de prestação de serviços.. Os resultados apontam que as vantagens mais atrativas para os trabalhadores são: Cobertura previdenciária; Contratação de um funcionário com menor custo; Isenção de taxas para o registro da empresa; Ausência de burocracia; Redução da carga tributária; Serviços gratuitos. Concluiu-se que a Lei 128/08, que trata do Microempreendedor Individual trouxe oportunidade de crescimento para os trabalhadores informais, com segurança jurídica e apoio de escritórios, prefeituras e o Serviço Brasileiro de Apoio às Micro e Pequenas Empresas (SEBRAE).

Palavras-chave: Formalização. Microempreendedor. Benefícios.

\section{INTRODUÇÃO}

O empreendedor sempre teve um papel importante para o desenvolvimento mundial, pois empreendedores são as pessoas que fazem a diferença, o empreendedor vê uma oportunidade de negócio onde todos veem dificuldades. No Brasil não há empecilhos para criação de uma empresa. Devido alguns fatores como o alto índice de desemprego, baixos salários, as pessoas sentem cada vez mais necessidade de procurar novas alternativas para adquirir renda (PORTAL DO EMPREENDEDOR).

Microempreendedor Individual é a pessoa que trabalha por conta própria e resolve legalizar sua situação com o governo (Município, Estados e União). Este pode ter renda anual de até $\mathrm{R} \$ 60.000,00$ não pode ser sócio de outra empresa, pode ter ainda um funcionário que deve receber um salário mínimo da categoria a que pertence. O Programa do microempreendedor individual foi lançado em $1^{\circ}$ de junho de 2009 , a segunda geração do programa foi lançada em 2010 simplificando o sistema e incluiu todas as unidades da

\footnotetext{
1 Acadêmico de Ciências Contábeis da UNEMAT - Campus de Tangará da Serra - MT, e-mail: Ricardo.cic@hotmail.com

${ }^{2}$ Professor do curso de Ciências Contábeis da UNEMAT - Campus de Tangará da Serra, e-mail: marcelo.evandro@unemat.br 
Benefícios do trabalho formal para os prestadores de serviços em obras de alvenaria na cidade de

Tangará da Serra - MT

Ricardo de Almeida

Marcelo Evandro Alves

federação. A facilidade e benefícios em relação a abertura de um novo negócio atrai inúmeras pessoas a entrarem neste programa (PORTAL DO EMPREENDEDOR, 2012).

O Brasil fechou o ano de 2012 com 2,6 milhões de empreendedores individuais cadastrados. O estado de Mato Grosso fechou o mesmo com 52.718 inscritos sendo que a cidade de Tangará da Serra fechou o ano com 1.583 trabalhadores inscritos, e o estado com maior número de inscrições foi o estado de São Paulo com 647.064. Para o ano de 2013 a expectativa de expansão do programa é ainda maior, pois já estão em vigor novas regras que ampliam os limites de enquadramento do Simples Nacional em 50\%, o teto passou de $\mathrm{R} \$ 36$ para R\$ 60 mil (PORTAL DO EMPREENDEDOR, 2013).

Diante do exposto, o problema abordado foi: Qual a importância da formalização para os trabalhadores prestadores de serviços em obras de alvenaria na cidade de Tangará da Serra $-\mathrm{MT}$ ?

O objetivo geral da pesquisa foi destacar a importância da formalização dos trabalhadores prestadores de serviços no ramo de obras de alvenaria na cidade de Tangará da Serra - MT.

Os objetivos específicos consistiram em apontar quais os benefícios que tiveram os trabalhadores após a formalização; Ressaltar a importância da formalização não só para o empreendedor, mas também para a sociedade num todo.

O principal objeto do estudo é constituído por pessoas físicas prestadoras de serviços que já se formalizaram e ainda não conhecem os benefícios e que atuam na prestação de serviços em obras de alvenaria na cidade de Tangará da Serra - MT.

Justifica-se este trabalho pela relevância de se conhecer as vantagens e benefícios que a formalização pode trazer para os trabalhadores informais. O estudo é importante para a sociedade que desfruta do trabalho destas pessoas, para o município que é um comprador de mercadorias e serviços, para as empresas que necessitam estar em dia com o fisco.

É também relevante para os acadêmicos, de forma que é um projeto recente do governo e pode ser alvo de várias discussões acerca do assunto, já que tem o objetivo de diminuir o desemprego do país, dando aos trabalhadores benefícios significativos tais como benefício previdenciário, carga tributária reduzida, contratação de um funcionário com menor custo, entre outros. Muitos trabalhadores ainda não se formalizaram, pois não tem conhecimento da figura de pessoa jurídica do Microempreendedor Individual e de suas vantagens comparado aos trabalhadores informais. 


\section{REFERENCIAL TEÓRICO}

\subsection{A Informalidade no Brasil}

O conceito de informalidade foi operacionalizado de diversas formas na década de 1990, a maior parte dos trabalhadores consideravam que o trabalho informal era formado por trabalhadores assalariados sem carteira de trabalho assinada e por pessoas que trabalhavam por conta própria (OLIVEIRA, ET AL, 2013).

Existem vários fatores que desestimulam os trabalhadores a se formalizarem, como o alto custo da legalização, falta de informação, baixa capacidade para pagamento dos impostos. Um dos grandes fatores para o surgimento de negócios informais no país é o desemprego, obrigando os trabalhadores a trabalhar informalmente (SILVEIRA, 2010).

O trabalho informal é aquele em que as atividades são executadas por conta própria, a margem da lei, especialmente se tratando da legislação previdenciária, o trabalhador não contribui com a previdência, não tem anotação na carteira de trabalho e previdência social (FATIMA, SILVA, 2006).

A informalidade atinge em sua grande parte as pequenas e microempresas que não têm condições de superar a burocracia, as que não tem condições de cumprir com o que determina as leis trabalhistas e previdenciárias, os gastos com contratação gerada por essas leis. Para empregar um funcionário legalmente, uma empresa tem de arcar com uma despesa de contratação (PASTORE, 2006).

\subsection{A importância do empreendedorismo}

O empreendedor move o mundo, faz girar a economia, sente prazer em contribuir e inovar. É um ser movido a realizações de toda ordem e não mede esforços para alcançar seus objetivos (MENDES, 2009).

Segundo Mendes (2009, p. 7) :

O empreendedor é o processo dinâmico de criar riqueza. A riqueza é criada por indivíduos que assumem os principais riscos em termos de patrimônio, tempo e/ ou comprometimento com a carreira, mas o valor deve de algum modo ser infundido pelo empreendedor ao receber e localizar as habilidades e os recursos necessários. 
Benefícios do trabalho formal para os prestadores de serviços em obras de alvenaria na cidade de

Tangará da Serra - MT

Ricardo de Almeida

Marcelo Evandro Alves

O candidato a empreendedor deve ir além de observar e conhecer os negócios a sua volta; ele precisa usar a criatividade para transpor ideias vencedoras de um negócio em outro (DEGEN, 2009).

Como uma forma de contribuição para a sociedade e realização pessoal, algumas pessoas são atraídas para o empreendedorismo, uma forma de contribuir positivamente para a comunidade em que vivem, fazendo bem de uma forma digna, sem fraudes, trabalhando honestamente, pagando seus impostos (LONGENECKER, 2007).

A Organização para Cooperação Desenvolvimento Econômico (OCDE) afirma que "o empreendedorismo é uma maneira de ver as coisas e um processo para criar e desenvolver atividades econômicas com base em risco, criatividade e inovação de gestão, no interior de uma organização nova ou já existente".

Empreendedorismo é o processo de criar algo novo com valor, dedicando o tempo e o esforço necessário, assumindo os riscos financeiros, psíquicos e sociais correspondentes e recebendo as consequentes recompensas da satisfação e da independência financeira e pessoal (LONGENECKER, 2007).

Para ambos os autores acima citados, os empreendedores se resumem em indivíduos que criam riquezas, assumem riscos, indivíduos que descobrem novas oportunidades no mercado, movem a economia do país, dedicam o tempo necessário a fim de inovar o mercado, usam a criatividade para alcançar seus objetivos.

Considera-se empresário quem exerce profissionalmente atividade econômica organizada para a produção ou a circulação de bens ou de serviços. Não se considera empresário quem exerce profissão intelectual, de natureza científica, literária, ou artística, ainda com o concurso de auxiliares ou colaboradores, salvo se o exercício da profissão constituir elemento de empresa. É obrigatória a inscrição do empresário no Registro Público de Empresas Mercantis da respectiva sede, antes do início de sua atividade (FIUZA, 2003).

\subsection{Microempreendedor Individual}

$\mathrm{Na}$ tentativa de formalizar os trabalhadores que se encontravam na informalidade, surgiu em 2008 no ordenamento jurídico brasileiro a figura do Micro empreendedor Individual (MEI). Um dos principais benefícios da formalização são os ligados a Previdência Social, contribuindo com a Previdência Social os trabalhadores podem usufruir dos recursos quando necessário. O público alvo são os vendedores ambulantes, eletricistas, marceneiros, 
Benefícios do trabalho formal para os prestadores de serviços em obras de alvenaria na cidade de

Tangará da Serra - MT

Ricardo de Almeida

Marcelo Evandro Alves

mecânicos, feirantes, pedreiros, pintores, sapateiros, pipoqueiros entre outros (RECEITA FEDERAL DO BRASIL, 2013).

Ao instituir o Microempreendedor Individual o Governo teve por objetivo a diminuir da informalidade, trazer a oportunidade de trabalhadores informais que antes não eram reconhecidos, se tornarem empresários, aumento de empregos formais, diminuição das obrigações tributárias, redução da carga tributária, o acesso a crédito para expandir o negócio. Com o emprego formal os trabalhadores tem a cobertura previdenciária garantindo o direito ao auxílio doença, acidente de trabalho, aposentadoria por idade após carência. No caso de doença, o trabalhador informal não tem nenhuma ajuda de custo quando se afasta do trabalho, já o trabalhador formal, com a cobertura previdenciária que a lei oferece, terá sua proteção garantida, há também o auxílio à microempreendedoras que precisam se afastar em caso de gravidez (PORTAL DO EMPREENDEDOR, 2013).

\subsection{Benefícios do Microempreendedor Individual}

O programa foi lançado em $1^{\circ}$ de julho de 2009 com o objetivo de formalizar os trabalhadores que atuam por conta própria. $\mathrm{O}$ interessado também não pode ter participação em outra empresa como sócio ou titular (SEBRAE, 2012).

Dentre os benefícios está o registro no Cadastro Nacional de Pessoas Jurídicas (CNPJ) o que facilita na emissão de notas fiscais, abertura de contas bancárias e pedidos de empréstimos além de conquistar novos clientes (PORTAL DO EMPREENDEDOR, 2012).

$\mathrm{Na}$ área de prestação de serviços, o MEI pagará apenas o valor fixo mensal de R \$ 39,90 que é destinado à Previdência Social, ao ICMS ou ISS, este valor é recolhido mensalmente por meio do Documento de Arrecadação do Simples Nacional (DAS), e sua emissão pode ser feita por meio do site do portal do empreendedor por qualquer pessoa que tenha um computador ligado à internet. O pagamento deve ser feito na rede bancária, casas lotéricas até o dia 20 de cada mês, conforme resolução $n^{\circ} 58$ de 2009 . Não se aplica a tributação de substituto tributário ou retenção de ISS sobre os serviços prestados. Essa quantia pode ser atualizada anualmente de acordo com o aumento do salário mínimo.

$\mathrm{Na}$ contratação de um funcionário o empresário pagará além do valor fixo, $8 \%$ de FGTS e INSS patronal de 3\% sobre o salário. Com o pagamento destas contribuições o empreendedor individual terá acesso a benefícios como salário maternidade, auxílio doença, 
Benefícios do trabalho formal para os prestadores de serviços em obras de alvenaria na cidade de

Tangará da Serra - MT

Ricardo de Almeida

Marcelo Evandro Alves

aposentadoria, entre outros, é importante lembrar que todos os demais direitos do trabalhador devem ser respeitados (PORTAL DO EMPREENDEDOR, 2012).

A seguir o quadro que mostra de forma sistemática os impostos que compõem o Documento de Arrecadação do Simples Nacional (DAS).

\begin{tabular}{l|lr}
\hline \multicolumn{2}{c}{ Tabela 1- Impostos que compõem o DAS } \\
\hline ICMS (ao estado, se comércio ou indústria) & $\mathrm{R} \$$ & 1,00 \\
ISS (ao município, se serviço) & $\mathrm{R} \$$ & 5,00 \\
INSS* & $\mathrm{R} \$$ & 33,90 \\
\hline
\end{tabular}

* Nota: A título de Contribuição para a Seguridade Social, relativos à pessoa do empresário na qualidade de contribuinte individual, corresponde a 5\% do salário mínimo vigente.

Fonte: Adaptado pelo autor

Além da redução da carga tributária, os empresários contábeis têm a oportunidade de protagonizar um grande trabalho social no país. Os escritórios de contabilidade farão gratuitamente o registro do empreendedor individual e a primeira declaração anual da categoria, conforme $\S 22-\mathrm{B}$ da Lei 128/2008. Na cidade de Tangará da Serra - MT a prefeitura municipal faz esta inscrição. O registro é feito através do Portal do Empreendedor no site. O SEBRAE também é um grande parceiro do empreendedor individual, oferecendo orientação. Os contadores devem estar sempre atentos à mudanças na legislação para que estejam sempre predispostos a informar, orientar os microempreendedores (FENACON, 2012).

\subsection{Prestação de Serviços}

O conceito de serviços para Lovelock e Wright (2006, p. 5) “ é um ato ou desempenho que cria benefícios para clientes por meio de uma mudança desejada no/ou em nome do destinatário do serviço".

As empresas prestadoras de serviços são as empresas que oferecem trabalhos especializados como transportes, educação, saúde, comunicação, lazer, serviços de 
Benefícios do trabalho formal para os prestadores de serviços em obras de alvenaria na cidade de

Tangará da Serra - MT

Ricardo de Almeida

Marcelo Evandro Alves

manutenção etc. Não produzem mercadorias, mas atividades profissionalizantes (CHIAVENATO, 1995).

Conforme o Ministério da Previdência Social, obra de construção civil é a construção, a demolição, a reforma ou a ampliação de edificação, de instalação ou de qualquer outra benfeitoria agregada ao solo ou do subsolo (MINISTÉRIO DA PREVIDENCIA SOCIAL, 2013).

A prestação de serviços é uma das que tem maior importância na econômica brasileira, além disso responde por uma parte importante do PIB nacional, garante empregos, por esta razão, os incentivos públicos e investimentos privados para empreedimentos de serviços aumentaram (ROQUE, 2010).

\section{METODOLOGIA}

Esta pesquisa se caracterizou como descritiva e exploratória quanto aos objetivos, pois objetivou averiguar quais são os benefícios que a formalização traria aos trabalhadores no ramo de obras de alvenaria na cidade de Tangará da Serra- MT.

A pesquisa descritiva tem como objetivo descrever as características de uma determinada população como idade, sexo, renda, nível de escolaridade. Uma de suas características mais significativas está na utilização de técnicas padronizadas na coleta de dados como questionários e observação sistemática (GIL, 2008).

Foi utilizado o método quantitativo quanto a abordagem do problema, pois foi feita uma pesquisa de campo, a fim de apontar aos trabalhadores informais a importância da formalização, as vantagens dos trabalhadores que se formalizaram, acessibilidade que antes só os demais empresários tinham.

A coleta de dados ocorreu nos meses de abril e maio de 2013. A população amostral foi composta de 40 Microempreendedores Individuais, com inscrição municipal, ou seja, que tem alvará de funcionamento e que atuam na área de prestação de serviços em obras de alvenaria na cidade de Tangará da Serra - MT, conforme relatório concedido pela Prefeitura Municipal, não foi possível obter resultado dos 44 pesquisados pela dificuldade do contato com estes trabalhadores. Alvenarias são construções em que se utilizam tijolos, pedras, vidros, cerâmica, colocados uns sobre os outros normalmente unidos por cimento, quem trabalha nestas construções são pedreiros, mestre de obras, serventes, azulejistas entre outros. 
Benefícios do trabalho formal para os prestadores de serviços em obras de alvenaria na cidade de

Tangará da Serra - MT

Ricardo de Almeida

Marcelo Evandro Alves

A pesquisa traduziu em números as informações, os dados levantados através da coleta. No processo de coleta de dados foi confeccionado questionário com questões fechadas, claras e objetivas a fim de levantar dados acerca do tema proposto, para que seja possível obter o resultado esperado.

Conforme Both (2004, p. 53) a "coleta de dados está relacionada ao levantamento de dados para obter uma investigação mais clara sobre todos os pontos envolvidos com a pesquisa".

Neste processo foi realizada investigação a partir da classe de trabalhadores formais indicadas neste trabalho, uma amostra com 40 trabalhadores, a fim de esclarecer algumas perguntas que surgem neste estudo.

\section{RESULTADOS E DISCUSSÕES}

Os resultados obtidos através da pesquisa, diante dos conceitos anteriormente apresentados sobre a figura de pessoa jurídica do microempreendedor individual, no qual foi elaborado um questionário para a coleta de dados, foram apresentados de acordo com as respostas dos pesquisados através de gráficos e tabelas.

Através da pesquisa constatou-se que todos os pesquisados são homens, isso por que é de conhecimento geral que o ramo da construção civil é predominantemente ocupado por homens. O trabalho da mulher na construção civil aumentou na última década conforme dados da Relação Anual de Informações Sociais (RAIS) do Ministério do Trabalho e emprego (MTE), porém isto não se percebe na cidade de Tangará da Serra - MT.

No Brasil, conforme pesquisa apresentada pelo SEBRAE no ano de 2012 com uma amostragem de 11.577 microempreendedores individuais em todo o território nacional selecionando cerca de 430 MEI por UF (UNIDADE FEDERATIVA), no ramo da construção civil, $95 \%$ são homens e $5 \%$ são mulheres, sendo o ramo de atividade que possuem mais trabalhadores do sexo masculino. Na mesma pesquisa, do total de Microempreendedores nas diversas áreas, $54 \%$ são do sexo masculino e $46 \%$ são do sexo feminino.

É possível observar através do gráfico 1 que 29 dentre os pesquisados tem a faixa etária acima dos 40 anos, seguido de 11 que estão na faixa de 31 à 40 anos. 
Benefícios do trabalho formal para os prestadores de serviços em obras de alvenaria na cidade de

Tangará da Serra - MT

Ricardo de Almeida

Marcelo Evandro Alves

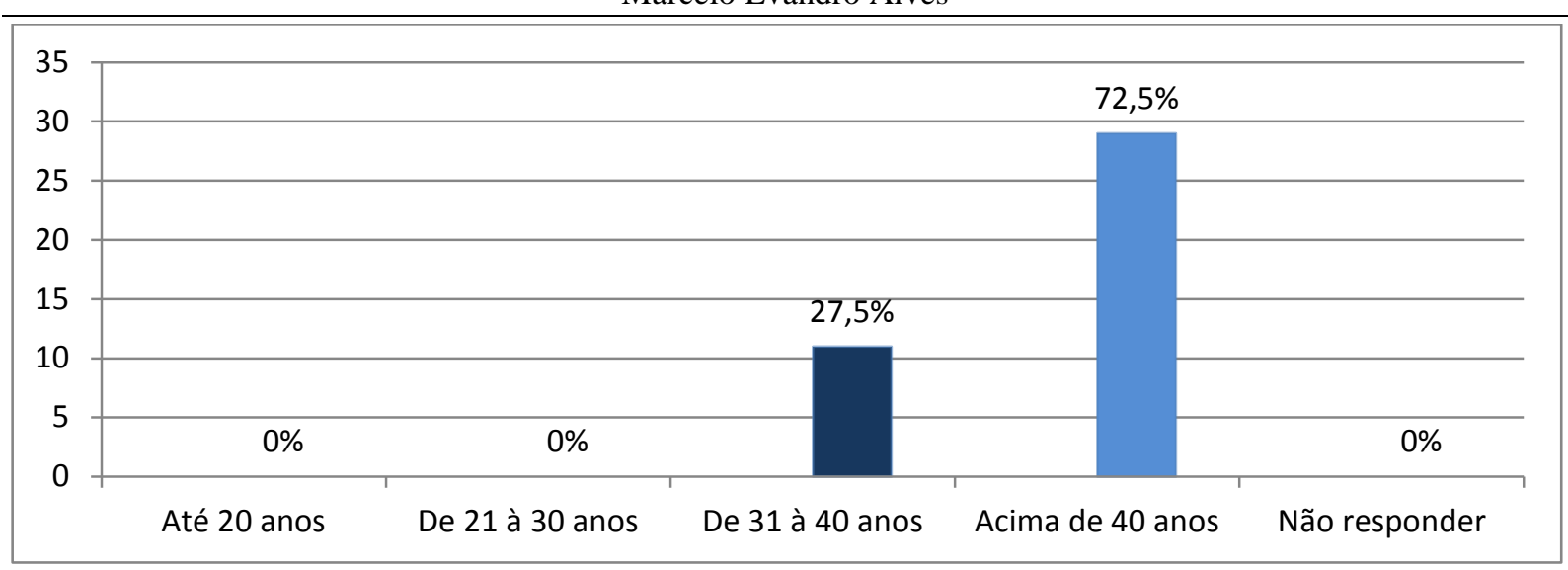

Fonte: Dados da pesquisa, 2013.

Do mesmo modo, de acordo com Souza 2010 em pesquisa realizada na cidade de Florianópolis-SC com 30 microempreendedores, 17 trabalhadores estão na faixa etária de 31 á 40 anos.

Na cidade de Nova Olímpia - MT, conforme Silva 2011 de uma amostra de 39 microempreendedores individuais formalizados 22,56\% fazem parte da faixa etária de 31 à 40 anos, em Tangará da Serra - MT conforme representado acima a maior parte dos pesquisados estão acima de 40 anos de idade.

Se tratando do tempo de atuação na área, foi possível perceber através do gráfico 2 que dentre os pesquisados, 18 tem mais de 10 anos de atuação na área, seguido dos que possuem de 6 à 10 anos de atuação, que foram 16 e os que possuem de 3 à 5 anos, 6 trabalhadores.

\section{Gráfico 2 - Tempo de atuação na área.}

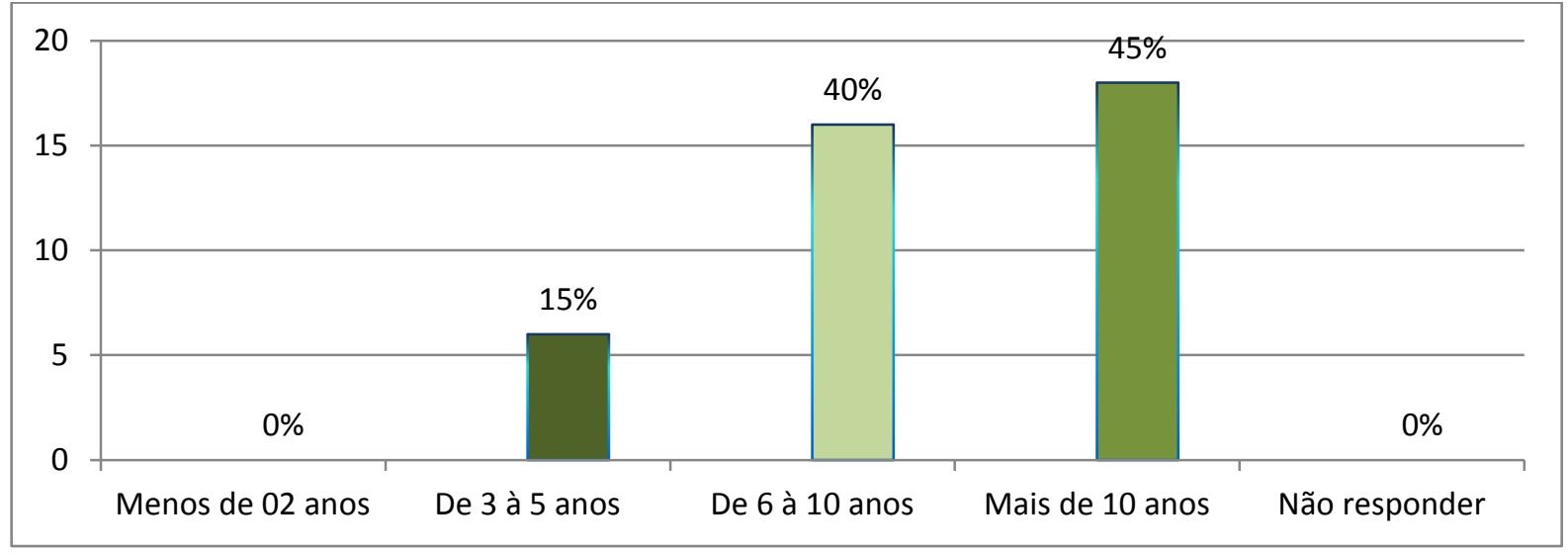

Fonte: Dados da pesquisa, 2013.

Através dos dados levantados foi possível identificar que todos os pesquisados não possuem especialização na área de obras de alvenaria, um total de $100 \%$. As instituições de 
Benefícios do trabalho formal para os prestadores de serviços em obras de alvenaria na cidade de

Tangará da Serra - MT

Ricardo de Almeida

Marcelo Evandro Alves

ensino da cidade de Tangará da Serra - MT não oferecem cursos na área de obras de alvenaria, neste caso a experiência obtida nesta profissão se tem com o tempo de atuação.

Na cidade de Rondonópolis-MT o Serviço Nacional de Aprendizagem Industrial (SENAI), oferece cursos de qualificação profissional nesta área com o título de pedreiro de alvenaria, os interessados devem ter 18 anos e devem ser alfabetizados. Conforme Souza, 2010, 46\% dos trabalhadores já trabalhavam na área informalmente e encontraram no MEI uma forma de exercer suas atividades com menor custo e garantir benefícios.

O gráfico 3 demonstra o ano em que ocorreu a formalização para Microempreendedor Individual (MEI). Dos pesquisados, apenas 1 formalizou-se no ano de 2010, no ano de 2011 e 2012 foram 18 trabalhadores que se formalizaram, e no ano de 2013 foram 3. Os dados indicam que nos dois últimos anos aumentou a quantidade de Microempreendedores.

Gráfico 3 - Ano da formalização para MEI .

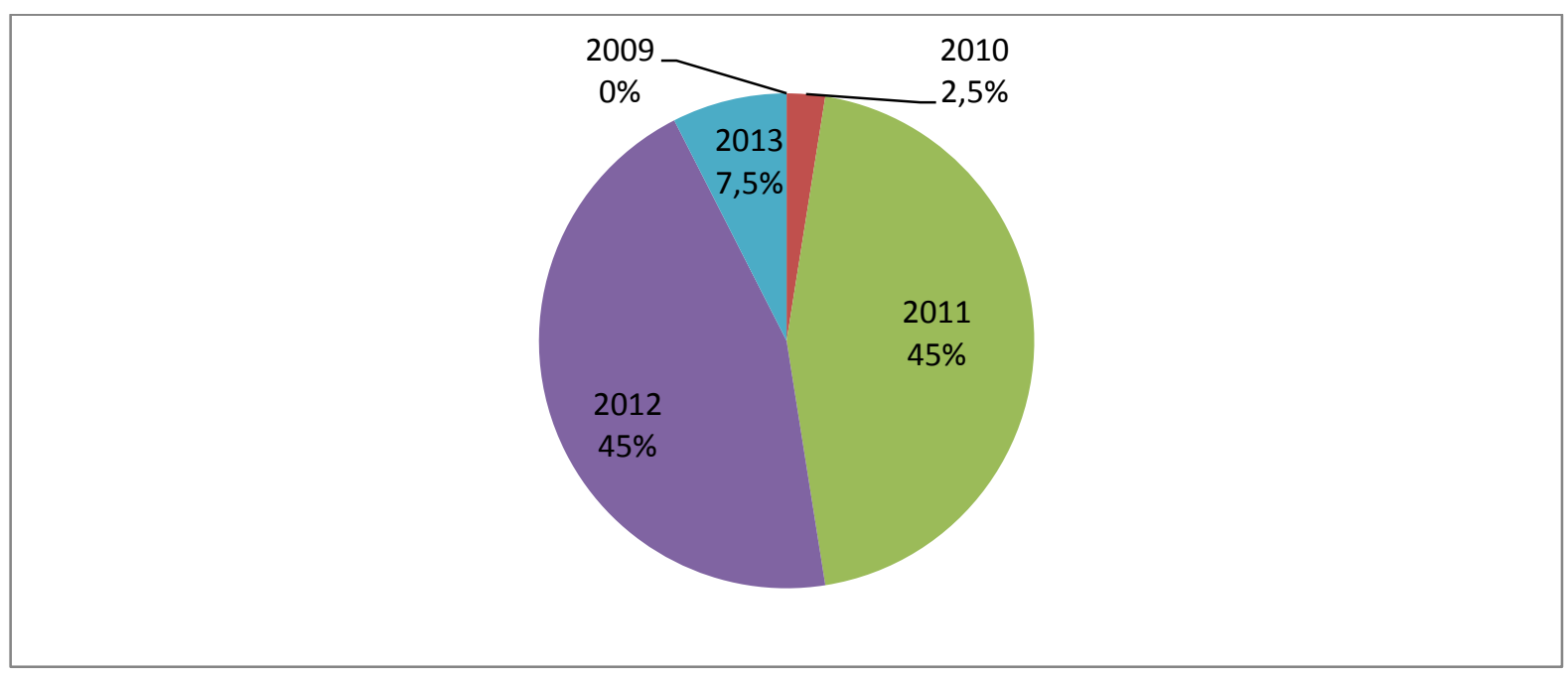

Fonte: Dados da pesquisa, 2013.

Confrontando o tempo de atuação na área conforme o gráfico 2, com o ano em que se tornaram microempreendedores individuais, 18 pessoas tem mais de 10 anos de profissão e se formalizaram recentemente, o que indica que foi uma forma de aproveitar os benefícios concedidos pela lei 128/2008, o que indica que o trabalhador atuou muitos anos na informalidade.

Os Microempreendedores Individuais contam com o apoio de alguns órgãos e empresas para auxiliar no processo de formalização na cidade de Tangará da Serra. Dentre Volume 3, Número 5 Revista UNEMAT de Contabilidade Jan./Jun. 2014 
Benefícios do trabalho formal para os prestadores de serviços em obras de alvenaria na cidade de

Tangará da Serra - MT

Ricardo de Almeida

Marcelo Evandro Alves

eles estão os escritórios de contabilidade, a Prefeitura Municipal e o SEBRAE, que é parceiro dos micro e pequenos empresários (PORTAL DO EMPREENDEDOR, 2013).

Conforme gráfico 4, dentre os pesquisados, 17 pessoas contaram com o apoio de escritórios de contabilidade da cidade para a formalização, 10 pessoas contaram com o auxílio da Prefeitura Municipal.

Gráfico 4 - Auxilio no processo de formalização para MEI.

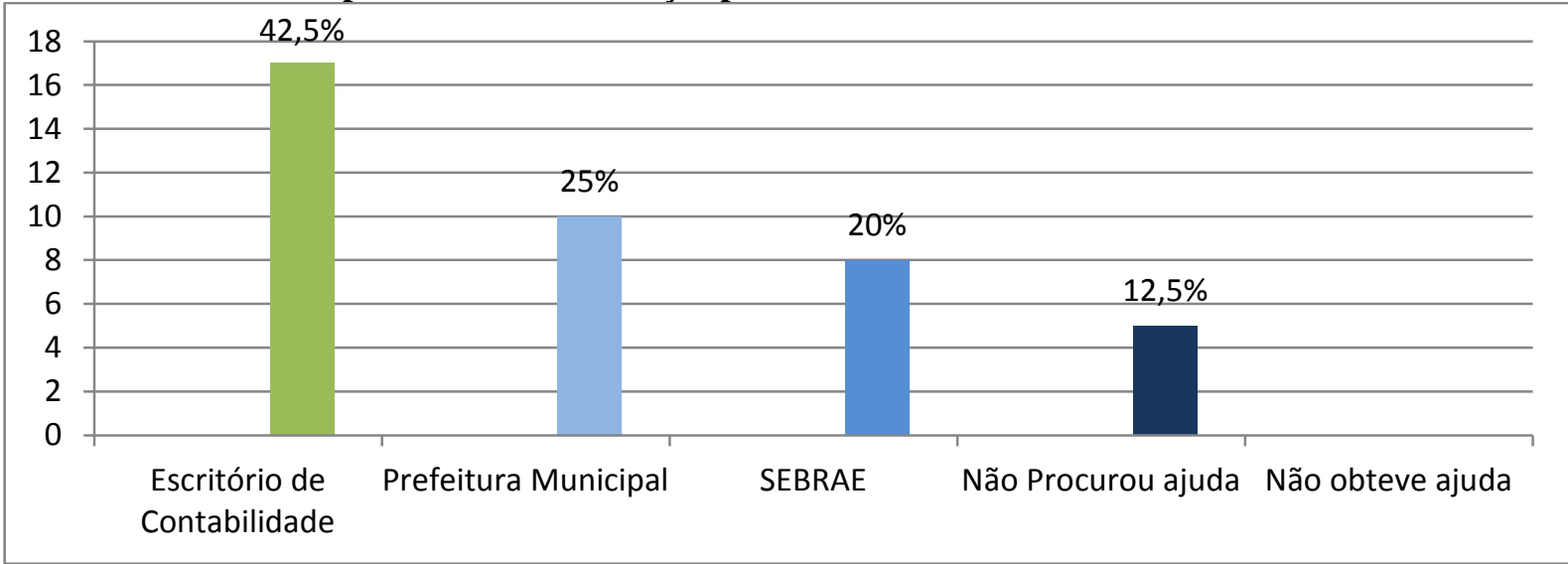

Fonte: Dados da pesquisa, 2013.

A Federação Nacional das Empresas de Serviços Contábeis e das Empresas de Assessoramento, Perícias, Informações e Pesquisas (FENACON) disponibiliza em seu site uma lista detalhada por cidade com os escritórios de contabilidade que estão disponíveis para ajudar os MEI no processo de formalização e na primeira declaração anual, serviços totalmente gratuitos. Esta lista possui endereço, telefone, o nome da empresa, o que o MEI precisa para encontrar com facilidade estes escritórios.

O processo para requerer alvará de funcionamento para MEI na prefeitura da Tangará da Serra é o mesmo que para as demais empresas, o que diferencia é que para o MEI o primeiro ano não é cobrado as taxas, o fiscal vai até o local e verifica se está em condições para atender ao público.

Ao requerer o alvará, é cobrado laudo de vistoria do Corpo de Bombeiros e laudo de vistoria de um profissional da área de engenharia ou arquiterura, estes profissionais avaliam Volume 3, Número 5 Revista UNEMAT de Contabilidade Jan./Jun. 2014 
Benefícios do trabalho formal para os prestadores de serviços em obras de alvenaria na cidade de

Tangará da Serra - MT

Ricardo de Almeida

Marcelo Evandro Alves

se o local está apto para funcionamento da empresa. A partir do segundo ano o MEI paga normalmente as taxas.

Se tratando de funcionário registrado, gráfico 5, constatou-se que 27 dos pesquisados tem funcionário com registro na carteira e 13 não possuem.

Gráfico 5 - Microempreendedores Individuais que tem funcionário com registro na carteira.

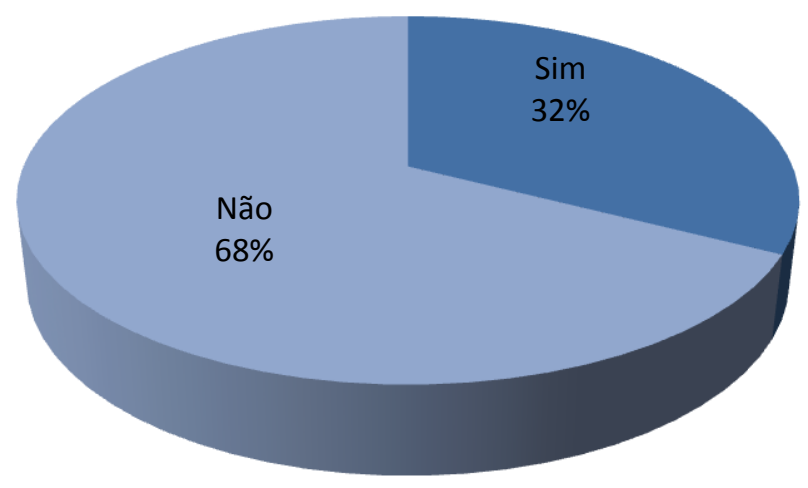

Fonte: Dados da pesquisa, 2013.

Diferente da pesquisa de Silva 2011 onde constou que 51\% de uma amostra de 39 microempreendedores individuais formalizados tem colaborador com registro na carteira e $49 \%$ não tem colaborador registrado.

Comparando a geração de empregos através dos microempreendedores individuais nos dois municípios constatou-se que em Nova Olímpia - MT a geração de empregos foi maior do que Tangará da Serra - MT.

Tabela 2. Resposta à questão: Atribua uma nota de 1 a 5 pelo grau de importância dos benefícios fornecidos pela formalização como MEI.

\begin{tabular}{lllllc}
\hline \multicolumn{1}{c}{ Benefícios } & $\mathbf{1}$ & $\mathbf{2}$ & $\mathbf{3}$ & $\mathbf{4}$ & $\mathbf{5}$ \\
\hline Cobertura previdenciária & 0 & 0 & 8 & 20 & 12 \\
\hline Contratação de um funcionário com menor custo & 0 & 0 & 9 & 26 & 5 \\
\hline Isenção de taxas para o registro da empresa & 0 & 1 & 8 & 21 & 10 \\
\hline
\end{tabular}


Benefícios do trabalho formal para os prestadores de serviços em obras de alvenaria na cidade de

Tangará da Serra - MT

Ricardo de Almeida

Marcelo Evandro Alves

\begin{tabular}{lccccc}
\hline Ausência de burocracia & 0 & 0 & 2 & 18 & 20 \\
\hline Acesso a serviços bancários, inclusive crédito & 0 & 2 & 10 & 15 & 13 \\
\hline Compras e vendas em conjunto & 10 & 5 & 16 & 5 & 4 \\
\hline Carga tributária reduzida & 0 & 0 & 3 & 17 & 20 \\
\hline Controles muito simplificados & 2 & 2 & 3 & 18 & 15 \\
\hline Facilidade para vender para o governo & 3 & 7 & 15 & 10 & 5 \\
\hline Serviços gratuitos & 0 & 0 & 5 & 25 & 20 \\
\hline Apoio técnico no SEBRAE na organização do negócio & 0 & 0 & 5 & 20 & 15 \\
\hline Possibilidade de crescimento como empreendedor & 0 & 0 & 1 & 15 & 24 \\
\hline Segurança jurídica & 0 & 2 & 3 & 13 & 22 \\
\hline Fon
\end{tabular}

Fonte: Dados da pesquisa, 2013.

Pode-se observar através da tabela 2 que os benefícios com maior relevância para os trabalhadores são: Cobertura previdenciária, nos quais $80 \%$ dos pesquisados atribuíram maior grau de importância; Contratação de um funcionário com menor custo, 67,5\% atribuiu maior grau de importância; Isenção de taxas para o registro da empresa, $75 \%$ dos pesquisados atribuíram maior grau de relevância; Ausência de burocracia, 95\%; Redução da carga tributária; Serviços gratuitos.

Conforme os dados levantados através do questionário aplicado, conclui-se que, o que atraiu a maior parte dos trabalhadores a se inscrever no MEI foi a ausência de burocracia para abrir seu próprio negócio, desde protocolos e taxas da junta comercial ou cartório; cobertura previdenciária, pois na qualidade de segurado pode usufruir dos auxílios do INSS; contratação de funcionário para ajudar no trabalho com menor custo, no que diz respeito a pagamento de impostos sobre a folha de pagamento; serviços gratuitos pois tem ajuda de parceiros, apoio técnico.

Em pesquisa apresentada em 2012 pelo SEBRAE, um dos benefícios ainda não utilizados por muitos trabalhadores é a possibilidade de venda de serviços e produtos para o governo, um mecanismo da Lei 128/2008, indica que o governo tem preferência para MEI em licitações.

$\mathrm{Na}$ cidade de Florianópolis no ano de 2010 conforme Souza, de 30 microempreendedores individuais, $44 \%$ apontaram como principal motivação para a formalização a possibilidade de emissão de nota fiscal e comprovação de renda.

Foi questionada a importância da formalização dos trabalhadores, no qual foi questionado se eles consideram importante que os trabalhadores se formalizem. Todos os pesquisados responderam que sim, ou seja, consideram importante a formalização dos trabalhadores que ainda são informais. 
Benefícios do trabalho formal para os prestadores de serviços em obras de alvenaria na cidade de

Tangará da Serra - MT

Ricardo de Almeida

Marcelo Evandro Alves

Conforme representado no gráfico 6 , dos 40 pesquisados 28 responderam que sim, aumentou a renda após a formalização, enquanto que 12 responderam que não houve aumento na renda.

Gráfico 6. Aumento da renda após a formalização.

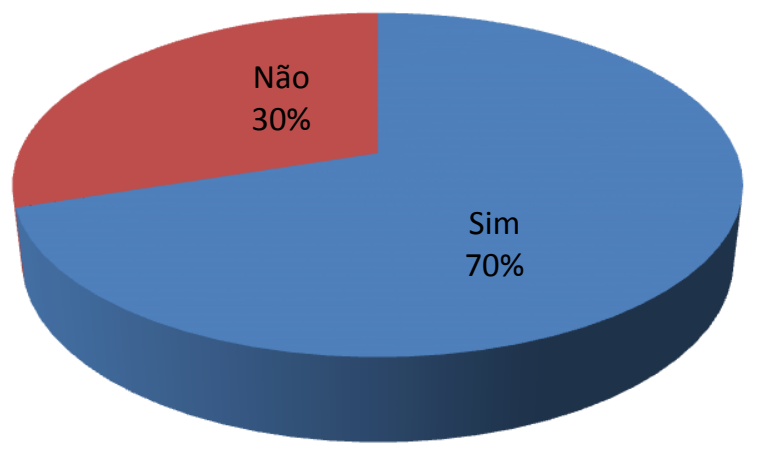

Fonte: Dados da pesquisa, 2013.

Conforme Lei Complementar 128/08, o Microempreendedor Individual pode ter até $\mathrm{R} \$$ 60.000,00 de receita anual, sendo até $\mathrm{R} \$$ 5.000,00 mensais. Foi questionado aos pesquisados se houve aumento na renda após a formalização.

Além de contribuir e trabalhar de forma regular, é possível obter lucratividade, um ponto positivo na formalização da atividade, prestam serviços para pessoas físicas e jurídicas, emitindo notas fiscais, contribuindo com o município através do pagamento mensal e fixo de Imposto sobre serviço (ISS).

Conforme pesquisa apresentada pelo SEBRAE 2012, 55\% dos microempreendedores afirmaram ter aumentado a renda, dentre eles, a maioria afirma ter aumentado também a negociação com outras empresas na venda de produtos e prestação de serviços, já que o MEI passou a emitir notas fiscais.

Foi questionado aos trabalhadores pesquisados se houve dificuldade no processo de formalização para MEI, o que se pode perceber com o gráfico 7 é que a maior parte não teve dificuldade, um total de 21 trabalhadores. Foram 8 os trabalhadores que não tiveram a atenção necessária nos escritórios de contabilidade (20\%) e com $10 \%$ estão os trabalhadores que não tiveram o apoio técnico do SEBRAE. 
Benefícios do trabalho formal para os prestadores de serviços em obras de alvenaria na cidade de

Tangará da Serra - MT

Ricardo de Almeida

Marcelo Evandro Alves

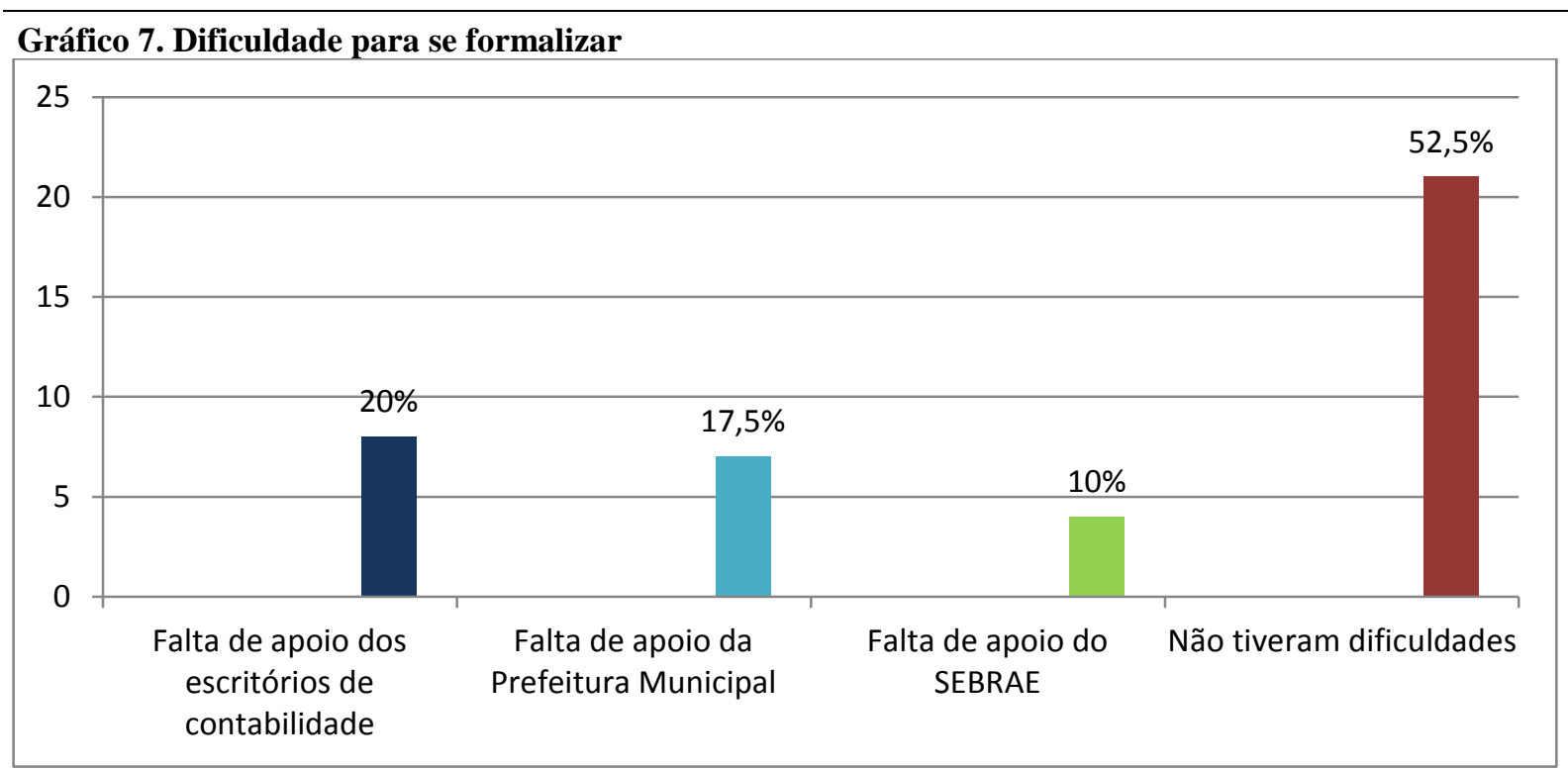

Fonte: Dados da pesquisa, 2013.

Conforme Souza, na pesquisa realizada em Florianópolis-SC, 77\% dos pesquisados de uma amostra de 30 trabalhadores, não estão tendo problemas no momento da formalização, o que indica que os profissionais responsáveis em repassar as informações estão atendendo as expectativas dos trabalhadores.

O fato de não ter dificuldades do processo de formalização revela que o processo é simples e não burocrático, a inscrição é feita pela internet e qualquer pessoa pode ter acesso, basta estar com os documentos em mãos e preencher os campos com atenção.

\section{CONSIDERAÇÕES FINAIS}

Considerando os dados levantados através da pesquisa de campo, avaliando as respostas dos pesquisados, pode-se afirmar que a Lei 128/08 que instituiu a figura jurídica do Microempreendedor Individual que tem como principal objetivo diminuir a informalidade no Brasil concede aos trabalhadores benefícios, oportunidades de crescimento profissional, cobertura previdenciária, ausência de burocracias, controle de receitas simplificadas, serviços gratuitos dentre outros, vantagens que são atrativas para trabalhadores que pretendem abrir um pequeno negócio, pois $100 \%$ dos pesquisados tem ciência de que é importante que os trabalhadores se formalizem.

Se tratando dos objetivos da pesquisa, pode afirmar que o objetivo geral e específico foram alcançados, pois através da pesquisa foi possível identificar sob a ótica dos pesquisados 
Benefícios do trabalho formal para os prestadores de serviços em obras de alvenaria na cidade de

Tangará da Serra - MT

Ricardo de Almeida

Marcelo Evandro Alves

a importância da formalização dos trabalhadores informais que trabalham em obras de alvenaria na cidade. A formalização é importante para a sociedade num todo, pois gera empregos, aumenta a renda, os trabalhadores recolhem seus impostos e podem vender mercadorias e serviços ao governo.

Com relação as vantagens que tem maior importância conforme a pesquisa, estão: Cobertura previdenciária; Contratação de um funcionário com menor custo; Isenção de taxas para o registro da empresa; Ausência de burocracia; Redução da carga tributária; Serviços gratuitos, o que indica que as vantagens vem sendo favoráveis para estes trabalhadores, garantindo benefícios além de aumentar a renda mensal, segurança jurídica com a inscrição no Cadastro Nacional de Pessoa Jurídica (CNPJ), aposentadoria e os auxílios concedidos pelo Instituto Nacional de Seguridade Social (INSS) que ampara os trabalhadores acidentados e doentes e salário maternidade de 5 meses, salário família para trabalhadores que tenham filhos menores que 14 anos.

Novas pesquisas poderão ser feitas acerca deste assunto, seja com trabalhadores nos diversos ramos atividades que prestam serviços, quanto aqueles que fazem parte do comércio, pois é uma oportunidade de abrir o próprio negócio trabalhando legalmente e também uma oportunidade de crescer como empreendedor. 
Benefícios do trabalho formal para os prestadores de serviços em obras de alvenaria na cidade de

Tangará da Serra - MT

Ricardo de Almeida

Marcelo Evandro Alves

\section{REFERÊNCIAS}

BOTH, Sergio José. Metodologia Científica: faça fácil sua pesquisa - 1 Ed. - Tangará da Serra (MT): Editora São Francisco, 2004.

BRASIL, Ministério do Desenvolvimento, Indústria e Comércio Exterior. Portal do Empreendedor. Brasília, 2012. Disponível em: $\langle$ http://www.portaldoempreendedor.gov.br/modulos/entenda/oque.php $>$ Acesso em: 24 de Maio. de 2013

BRASIL, Decreto-Lei ${ }^{\circ} 128$, de 19 de dezembro de 2008. Altera a Lei Complementar no 123, de 14 de dezembro de 2006. Planalto, Brasília, DF, 19 dez. 2008. Disponível em:

< http://www.planalto.gov.br/ccivil_03/leis/lcp/lcp128.htm> Acesso em: 21 de Jun. de 2013.

BRASIL, Receita Federal, Simples - Microempresa (ME) e Empresa de Pequeno Porte (EPP) Acessória de Comunicação - Ascom. Brasília, 2011. Disponível em:

http://www.receita.fazenda.gov.br/pessoajuridica/dipj/2004/pergresp2004/pr110a202.htm

Acesso em: 24 de Maio de 2013.

BRASIL, Ministério do Desenvolvimento, Indústria e Comércio Exterior. Notícias. Brasília, 2011. Disponível em:

<http://www.portaldoempreendedor.gov.br/modulos/noticias/noticia197.php> Acesso em: 20 de Maio de 2013.

BRASIL, Ministério da Previdência Social, Construção Civil, Brasília, 2013. Disponível em: http://www.mpas.gov.br/conteudoDinamico.php?id=383

CHIAVENATO, Idalberto. Vamos abrir um novo negócio? - 1 Ed. - São Paulo: Makron Books, 1995.

DEGEN, Ronald Jean. O empreendedor: empreendedor como opção de carreira. $1^{\circ}$. Ed. São Paulo: Pearson Prentice Hall, 2009.

FATIMA, Juvencio José; SILVA, Duarte Maria de Fatima. O trabalhado informal de fabricantes de pranchas de surfe: Uma análise das condições de saúde e trabalho. Revista brasileira de cineantropometria \& desempenho humano. Florianópolis, 2006

FEDERAÇÃO NACIONAL DAS EMPRESAS DE SERVIÇOS CONTÁBEIS E DAS EMPRESAS DE ASSESSORAMENTO, PERÍCIAS, INFORMAÇÕES E PESQUISAS FENACON. Microempreendedor Individual. Brasília, 2012. Disponível em: $<$ http://www.fenacon.org.br/microempreendedor.cshtml $>$ Acesso em 24 de setembro de 2012.

FIUZA, Ricardo. Novo Código Civil Comentado. $1^{\circ}$ E. $7^{\circ}$ Tiragem. - São Paulo: Saraiva, 2003.

GIL, Antonio Carlos. Métodos e técnicas de pesquisa social. $6^{\circ}$ Ed. - São Paulo: Atlas, 2008. 
Benefícios do trabalho formal para os prestadores de serviços em obras de alvenaria na cidade de

Tangará da Serra - MT

Ricardo de Almeida

Marcelo Evandro Alves

JULIEN, Pierre-André. Empreendedorismo regional e a economia do conhecimento. - São Paulo: Saraiva 2010.

LONGENECKER, Justin G. et al. Administração de pequenas empresas. São Paulo:

Thomson Learning, 2007.

LOVELOCK, Cristopher; WRIGHT, Lauren. Serviços: marketing e gestão. São Paulo:

Saraiva , 2006.

MACHADO, A. F.; PENIDO, M.; OLIVEIRA, J. M. de. Análise de sobrevivência na posição de trabalhador por conta própria no Brasil metropolitano (1997 a 2001)

MARION, José Carlos. Contabilidade Básica -10. Ed. - São Paulo: Atlas, 2009.

MENDES, Jerônimo. Manual do Empreendedor - 1 Ed. - São Paulo: Editora Atlas S/A, 2009.

OLIVEIRA, Euzira Lucia de; GIVISIEZ, Gustavo Henrique Naves; SARDENBERG, Kamila. Perfil do emprego no Brasil: análise de 1990 a 2010 - Niterói. 2013

PASTORE, José. Trabalho apresentado no Congresso da Industria, FIESP, São Paulo, 2006. Disponível em < http://www.josepastore.com.br/artigos/em/em_038.htm>. Acessado em : 15 Nov. de 2013.

ROQUE, Nathaly Campitelli. A prestação de serviços e o Código de Defesa do Consumidor: Os cuidados que devem ser tomados pelo fornecedor. Olimpia, 2010.

SANTOS et al, José Luiz. Contabilidade Geral - 3. Ed. - São Paulo: Atlas, 2011.

SERVIÇO BRASILEIRO DE APOIO ÁS MICRO E PEQUENAS EM EMPRESAS -

SEBRAE.. Perfil do Microempreendedor Individual 2012. Brasília, 2012. Disponível em:

< http://www.sebrae.com.br/estudos-e-pesquisas/ >. Acesso em: 20 Set. 2013.

SILVA, Fernanda Lima Araújo. A formalização do Microempreendedor Individual (MEI) no município de Nova Olímpia/MT - Nova Olímpia. 2011.

SILVEIRA, Jane Paula. Empreendedor Individual e os impactos pós-formalização. Patos de Minas, 2010.

SOUZA, Dayanne Marlene. Os principais benefícios proporcionados ao trabalhador informal para formalização através do Microempreendedor Individual. Monografia (Curso de Ciências Contábeis) - Universidade Federal de Santa Catarina, Florianópolis, 2010. 